LAWRENCE LIVERMORE N A T IO N A L LABORATORY

\section{Efficient Pumping Schemes for High Average Brightness Collisional X-ray Lasers}

R. Keenan, J. Dunn, V. N. Shlyaptsev, R. F. Smith, P. K. Patel, D. F. Price

October 16, 2003

SPIE

San Diego, CA, United States

August 3, 2003 through August 8, 2003 
This document was prepared as an account of work sponsored by an agency of the United States Government. Neither the United States Government nor the University of California nor any of their employees, makes any warranty, express or implied, or assumes any legal liability or responsibility for the accuracy, completeness, or usefulness of any information, apparatus, product, or process disclosed, or represents that its use would not infringe privately owned rights. Reference herein to any specific commercial product, process, or service by trade name, trademark, manufacturer, or otherwise, does not necessarily constitute or imply its endorsement, recommendation, or favoring by the United States Government or the University of California. The views and opinions of authors expressed herein do not necessarily state or reflect those of the United States Government or the University of California, and shall not be used for advertising or product endorsement purposes. 


\title{
Efficient Pumping Schemes for High Average Brightness Collisional X-ray Lasers
}

\author{
R. Keenan ${ }^{\mathrm{a}}$, J. Dunn ${ }^{\mathrm{a}}$, V.N. Shlyaptsev ${ }^{\mathrm{b}}$, R.F. Smith ${ }^{\mathrm{a}}$, P.K. Patel ${ }^{\mathrm{a}}$ and D.F. Price ${ }^{\mathrm{a}}$ \\ ${ }^{a}$ Lawrence Livermore National Laboratory, Livermore, CA 94550 \\ ${ }^{\mathrm{b}}$ University of California Davis-Livermore, Livermore, CA 94550
}

\begin{abstract}
Advances in transient collisional x-ray lasers have been demonstrated over the last 5 years as a technique for achieving tabletop soft $\mathrm{x}$-ray lasers using $2-10 \mathrm{~J}$ of laser pump energy. The high peak brightness of these sources operating in the high output saturation regime, in the range of $10^{24}-10^{25} \mathrm{ph} . \mathrm{mm}^{-2} \mathrm{mrad}^{-2} \mathrm{~s}^{-1}(0.1 \% \mathrm{BW})^{-1}$, is ideal for many applications requiring high photon fluence in a single short burst. However, the pump energy required for these $\mathrm{x}$-ray lasers is still relatively high and limits the $\mathrm{x}$-ray laser repetition rate to 1 shot every few minutes. Higher repetition rate collisional schemes have been reported and show some promise for high output in the future. We report a novel technique for enhancing the coupling efficiency of the laser pump into the gain medium that could lead to enhanced x-ray inversion with a factor of ten reduction in the drive energy. This has been applied to the collisional excitation scheme for Ni-like Mo at $18.9 \mathrm{~nm}$ and x-ray laser output has been demonstrated. Preliminary results show lasing on a single shot of the optical laser operating at $10 \mathrm{~Hz}$ and with $70 \mathrm{~mJ}$ in the short pulse. Such a proposed source would have higher average brightness, $\sim 10^{14} \mathrm{ph} . \mathrm{mm}^{-2} \mathrm{mrad}^{-2} \mathrm{~s}^{-1}(0.1 \% \mathrm{BW})^{-1}$, than present bending magnet $3^{\text {rd }}$ generation synchrotron sources operating at the same spectral range.
\end{abstract}

Keywords: x-ray lasers, bright x-ray sources, laser-produced plasmas

\section{INTRODUCTION}

The major goal of x-ray laser research has been improvement in efficiency, towards table-top x-ray lasers [1] that may be used for applications such as picosecond x-ray laser interferometry of dense plasmas [2]. Figure 1 shows how advances over the years have lead to lower pumping energy requirements and higher repetition rate of the optical pump laser. When the x-ray laser was first demonstrated in the mid '80s [3] kilojoules of optical pump energy were required. The $\mathrm{x}$-ray laser was produced by transverse pumping where the optical pump beam is focused into a line on a thin foil target creating a plasma column along which the x-ray laser is amplified with high gain. When the target was irradiated with a low energy pulse a few ns before the main pulse an improvement in x-ray laser output was observed [4]. The low energy pre-pulse forms a pre-plasma where the main pulse is absorbed more efficiently and reduced density gradients lead to reduced refraction and better propagation of the $\mathrm{x}$-ray laser beam. This pre-pulse technique, along with a reduction in the optical pump pulse duration from $\sim 1 \mathrm{~ns}$ to $\sim 100 \mathrm{ps}$, improved efficiency allowing production of saturated $\mathrm{x}$-ray lasers with an optical pump laser of $\sim 100-200 \mathrm{~J}$ pump energy $[5,6]$. These saturated $\mathrm{x}$-ray lasers operating in the quasi steady state regime (QSS) have operated with pump energy as low at $30 \mathrm{~J} \mathrm{[7],} \mathrm{have} \mathrm{produced} \mathrm{x-ray} \mathrm{laser} \mathrm{outputs} \mathrm{of} \mathrm{a} \mathrm{few} \mathrm{mJs}$ [8] and wavelengths down to $5.8 \mathrm{~nm}$ [9]. However, very large, national scale facilities are still required to produce these $\mathrm{x}$-ray lasers with the repetition rate limited to a few shots per day (Figure 1).

A further advance came with the development of the chirped pulse amplification (CPA) technique as smaller optical pump lasers could produce high irradiance in short pulses. The x-ray laser produced by transient collisional excitation (TCE), where a ns pre-pulse is followed by a short $\sim 1$ ps pulse that pumps the population inversion, further reduced the required pumping power to $10 \mathrm{~J}[10]$. Saturated operation of these $\mathrm{x}$-ray lasers has been demonstrated at wavelengths as low at 7.3nm [11] and with output pulse durations of 2 ps [12]. Figure 1 shows the optical pump parameters of the CPA COMET laser at LLNL, with $5 \mathrm{~J}$ pump energy and a repetition rate of once ever 4 minutes a saturated Pd $\mathrm{x}$-ray laser at $14.7 \mathrm{~nm}$ has been demonstrated [ $1 \beta$ with a pulse duration of $2.4-5 \mathrm{ps}$ [14]. Due to the short duration of the gain in the TCE scheme a traveling wave pump, with velocity $c$, is required so that each part of the target experiences gain as the $\mathrm{x}$-ray laser propagates along it. 


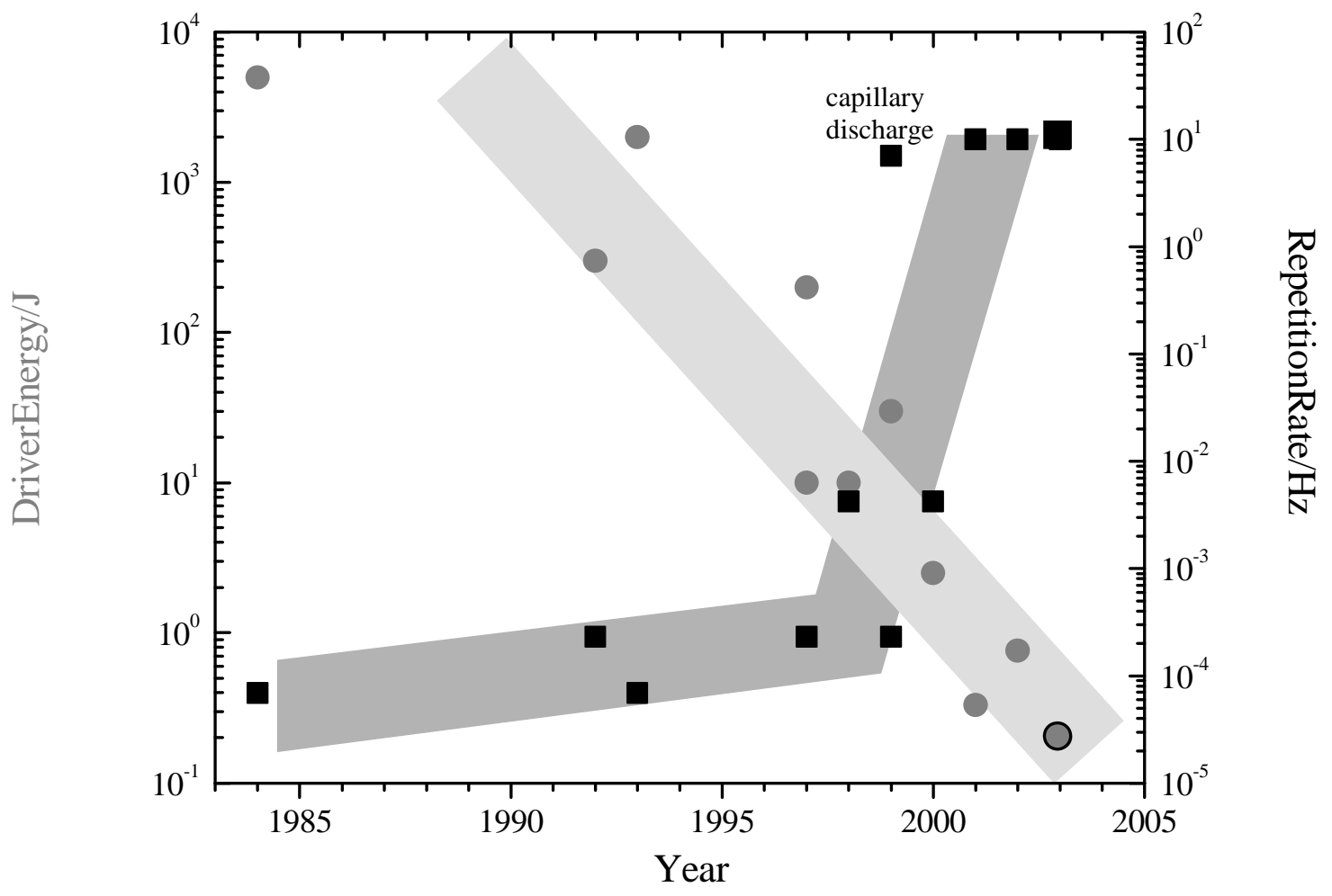

Figure 1 Time line of optical lasers pump energy (round symbols) and repetition rate (square symbols) used to pump x-ray lasers

A longitudinal pumped x-ray laser, where the optical pump beam is focused at high intensity into the end of the plasma column, is appealing since it allows efficient traveling-wave pumping and therefore co-propagation with the x-ray laser pulse. Saturated outputs have been produced from OFI pumped x-ray lasers, Pd-like Xe at $41.8 \mathrm{~nm}$ [15] and Ni-like $\mathrm{Kr}$ at $32.8 \mathrm{~nm}$ [16] have been demonstrated. These lasers were pumped with energy $<1 \mathrm{~J}$ and a repetition rate of $10 \mathrm{~Hz}$ as shown in Figure 1. A longitudinal pumped Ni-like Mo x-ray laser at $18.9 \mathrm{~nm}$ has also been demonstrated [17], where a 300 ps pre-pulse was incident normal to the target creating a preplasma which was then pumped by a short pulse from the longitudinal direction. This laser operated with a total pump energy of $150 \mathrm{~mJ}$ and produced a highly directional output but was not saturated. Figure 1 also shows an x-ray laser not pumped with an optical laser (so optical driver energy is not shown), the table-top capillary discharge laser operating at $46.9 \mathrm{~nm}$, which has produced millijoule level laser pulses at a repetition rate of several $\mathrm{Hz}$ [18].

The transverse and longitudinal pumping both have limitations. In the transverse mode most of the pump energy is absorbed near the critical surface at $10^{21} \mathrm{~cm}^{-3}$ and not in the active gain region at $10^{20} \mathrm{~cm}^{-3}$ electron density required for many of the mid-Z $\mathrm{x}$-ray lasers. In this higher density region high density gradients exists and refraction limits propagation of the $\mathrm{x}$-ray laser. So low laser coupling efficiency is one of the main issues for transverse pumping. Longitudinal pumped lasers have potentially higher efficiency. However, they must overcome considerable absorption, refraction, and relativistic self-focusing of the high intensity short pulse optical pump through the plasma. This reduces the plasma column length and requires a lower density regime hence limiting to longer wavelength $\mathrm{x}$-ray lasers This paper describes a novel pumping scheme, which will improve the efficiency of x-ray lasers and has allowed a low pump power $(\sim 150 \mathrm{~mJ})$ high repetition rate $(10 \mathrm{~Hz})$ optical pump laser to create an x-ray laser below $20 \mathrm{~nm}$. This achievement for 2003 is shown in Figure 1 but this result is preliminary, saturation has not been achieved yet and work is currently under way to measure the gain and GL product. 


\section{GRAZING INCIDENCE PUMPING}

This pumping scheme uses a long prepulse and a short pumping pulse, as in the usual transverse schemes, but with a factor of $20 \times$ less energy that used for other TCE x-ray lasers [13]. In this case a 200 ps pre-pulse is incident on the target in a line focus creating a pre-formed plasma with a tailored density profile. After a certain delay, chosen to optimize this density profile, the $\sim 1$ ps short pulse is incident on the target, also in a line focus, at grazing incidence. An overhead schematic of the pumping arrangement is shown in

Figure 2. The short pulse beam traverses the density region of interest being simultaneously strongly absorbed and refracted. However this refraction is of benefit to the pumping as an angle of incidence is chosen such that at a given electron density the short pulse is refracted exactly into lasing region, and after the turning point has passed it twice, maximizing the deposition of laser energy within the optimal gain region. The traveling wave is inherent in this scheme and each section of the short pulse line focus pumps a new section of target as for transverse pumping. The $\mathrm{x}$-ray laser beam propagates along the axis of the plasma column and is strongly amplified. This grazing incidence pumping (GRIP) which selectively pumps the gain region is a novel concept and should dramatically improve the efficiency of laserpumped x-ray lasers.

The refraction is used in the GRIP scheme to optimally couple the optical drive beam. Since the absorption in plasma corona is increasing as $1 / \sin (\phi)$ of grazing angle $\phi$ and refraction gradually turns the rays $\phi->0$, the absorption efficiency is dramatically increased up to the turning point, where plasma is pumped longitudinally. Also, the density has maximum at this point thus facilitating absorption here. The short pulse is then refracted back into the gain region after experiencing the maximum density of the gain region and is absorbed additionally. The refraction also works to direct the pumping power precisely into gain region because all rays with a given initial angle will pass through the same density at turning point independent of density gradients. RADEX raytracing in Figure 3 shows how refraction of the pump beam occurs at a given electron density and how the turning of the pump beam back into the gain region increases the path length and hence absorption. The density at the turning point is optimized for a particular x-ray laser from atomic kinetics and refraction of the x-ray signal itself. Given this selected density and the wavelength of pumping laser the angle of incidence is chosen. For a maximum density within the gain region $n_{\mathrm{e} 0}$ and the critical density $\mathrm{n}_{\mathrm{ec}}$ for the optical pump beam the required angle of incidence is obtained from $\phi_{r}=\sqrt{n_{e 0} / n_{e c}}$ [19]. With a maximum density of $\mathrm{n}_{\mathrm{e} 0}=1 \times 10^{20} \mathrm{~cm}^{-3}$ for the gain region and the critical density for the $800 \mathrm{~nm}$ optical pump of $\mathrm{n}_{\mathrm{ec}}=1.74 \times 10^{21} \mathrm{~cm}^{-3}$ the angle of incidence $\phi_{r}=13.7^{\circ}$. This angle is measured relative to the $\mathrm{x}$-ray laser media axis, not relative to the normal, in the same way the deflection angle of the $\mathrm{x}$-ray laser due to refraction is measured.

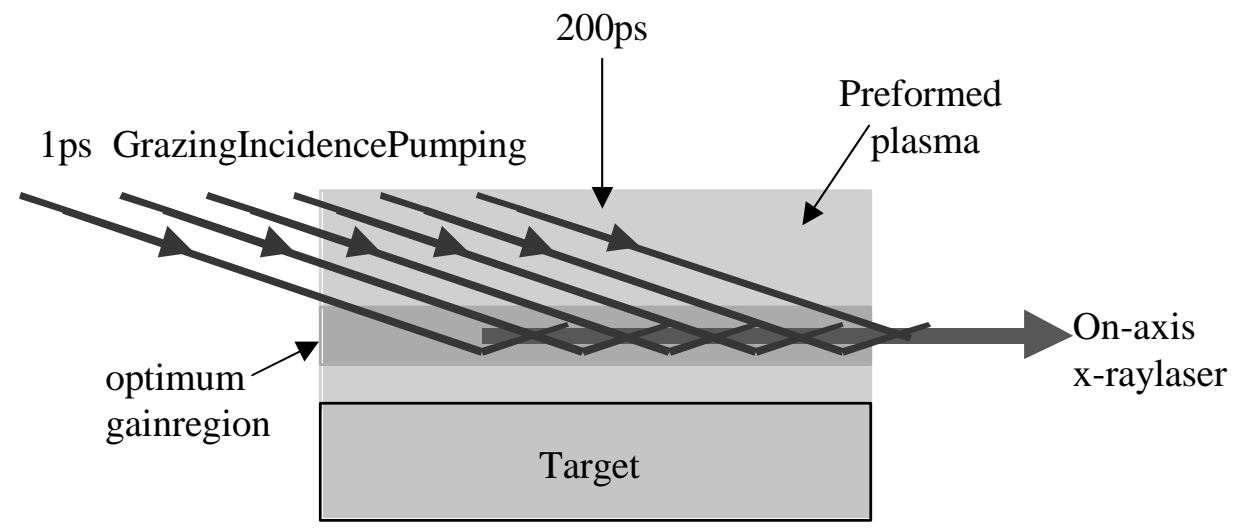

Figure 2 Schematic of grazing incidence pumping (GRIP) scheme. First a pre-formed plasma is produced, using a 200 ps pulse incident normal to the flat target, generating an optimum gain region. GRIP geometry uses $\sim 1 \mathrm{ps,} 800 \mathrm{~nm}$ wavelength laser to strongly heat this region producing efficient on-axis $\mathrm{x}$-ray lasing 


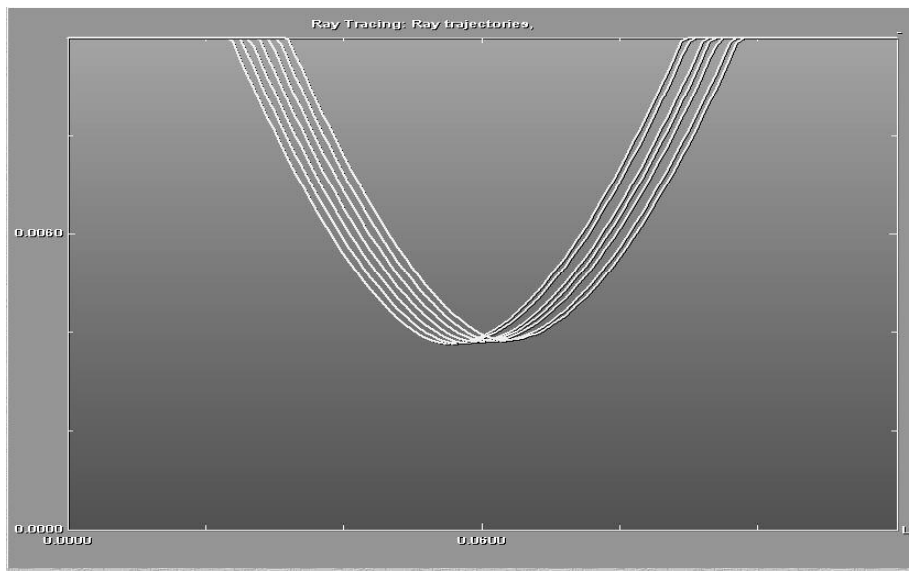

Figure 3 RADEX ray trace of $800 \mathrm{~nm}$ pump beam in preformed plasma

Figure 4 shows RADEX modeling carried out for the Ni-like Mo x-ray laser at $18.9 \mathrm{~nm}$. The long pulse, $200 \mathrm{ps}$ in duration, is incident normal to the target with $120 \mathrm{~mJ}$ total energy giving an intensity of $1.5 \times 10^{11} \mathrm{~W} / \mathrm{cm}^{2}$. The short pulse, 4 ps in duration, with $100 \mathrm{~mJ}$ total energy gives an on target intensity of $5 \times 10^{12} \mathrm{~W} / \mathrm{cm}^{2}$. The long pulse creates a preformed plasma with particular electron density gradients. At 500 ps after the peak of the long pulse an optimum electron density profile is created with electron densities of $0.5-1 \times 10^{20} \mathrm{~cm}^{-3}$ in the gain region. The gain region exists $15-30 \mu \mathrm{m}$ from the target and is shown as the shaded area in Figure 4. Shallow density gradients are present here, which improve the propagation of the $\mathrm{x}$-ray laser beam. The short pulse is incident at this time. The two cases of $14^{\circ}$ grazing incidence angle to the target and normal incidence are compared with the same pump energy. Figure 4 shows that the laser energy is absorbed within the gain region for grazing incidence pumping compared to at critical density for normal incidence. There is also a corresponding increase in temperature up to $250 \mathrm{eV}$ within the gain region. Further modeling of this scheme is described elsewhere [20]. This increase in absorption, from 5-8\% in the case of normal incidence to $50 \%$ for grazing incidence, corresponds to an improvement in efficiency where a saturated x-ray laser may be pumped with an optical laser of reduced pump power and at an increased repetition rate.

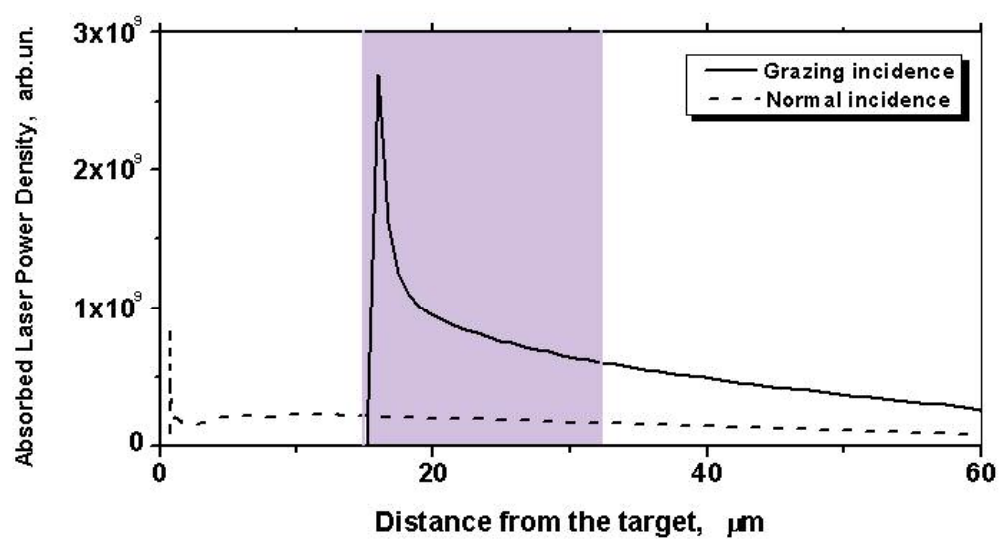

Figure 4 RADEX modeling for Ni-like Mo at $18.9 \mathrm{~nm}$ of absorbed laser energy for normal and grazing incidence pumping with the gain region shown as the shaded area 


\section{EXPERIMENTAL SETUP}

The JANUSP $800 \mathrm{~nm}$ Ti:sapphire laser at LLNL can operate in two modes, high power or high repetition rate. In the $10 \mathrm{~Hz}$ mode up to $300 \mathrm{~mJ}$ before compression is available to generate the two beams. This $10 \mathrm{~Hz}$ operation will allow us to demonstrate a high average brightness $\mathrm{x}$-ray laser. In the high power mode $15 \mathrm{~J}$ per shot can be produced with the laser fired every 30 minutes. These high energy shots would allow lasing at shorter wavelengths

The experimental arrangement is shown in Figure 5. The $300 \mathrm{~mJ}$ output of the JANUSP laser firing at $10 \mathrm{~Hz}$ is split after the first laser table, $100 \mathrm{~mJ}$ into the long pulse arm, $200 \mathrm{~mJ}$ into the compressor to produce the short pulse. The long pulse is increased in size then focused using a cylindrical and spherical lens creating a line focus $7 \mathrm{~mm} \times 25$ um with the $80 \mathrm{~mJ}$ incident on target give an intensity of $2 \times 10^{11} \mathrm{~W} / \mathrm{cm}^{2}$. The short pulse comes into the chamber from the compressor, off a $45^{\circ}$ mirror onto an on axis parabola tilted to give an incidence angle on target of $14^{\circ}$. A line focus $7 \mathrm{~mm}$ x $50 \mathrm{um}$ is produced. The on target energy was $70 \mathrm{~mJ}$ after losses in the compressor. The compressor was optimized with a pulse duration of $\sim 125 \mathrm{fs}$, giving an intensity of $1.5 \times 10^{14} \mathrm{~W} / \mathrm{cm}^{2}$. A 4 ps pulse would have given the required intensity of $5 \times 10^{12} \mathrm{~W} / \mathrm{cm}^{2}$. The delay between the beams could be adjusted from $0-1000 \mathrm{ps}$. The target is an $8 \mathrm{~mm}$ long solid slab of Mo mounted on a xyz translation stage. The line foci were imaged with an achromat at $25 \times$ magnification onto a charge-coupled device (CCD). The lens was on a motorized mount so that the overlap of the two beams could be checked along the entire length of the target while under vacuum. A spectrometer using a $1200 \mathrm{l} / \mathrm{mm}$ grating [21] was setup to image the target plane to a back-thinned CCD. Typically 20 shots were taken on a single target position with the CCD integrating over $2 \mathrm{~s}$. Spectra could also be recorded with a single laser shot on target. Aluminum filters $(0.3-2 \mu \mathrm{m}$ thick) were placed in front of the spectrometer to eliminate visible light, with a $0.3 \mu \mathrm{m}$ filter used for most shots. The on axis parabola was selected as it produced a line focus with the required grazing incidence to the target while remaining inexpensive and simple. The line focus produced by the optic was checked by ray-tracing and found to be of high quality, as Figure 6 a) shows, within a $8 \mathrm{~mm}$ long by 25 um slit. A traveling wave was also achieved with a velocity along the target of $0.94-0.98$ c for $10-20^{\circ}$ angle of incidence as shown in Figure 6 b)

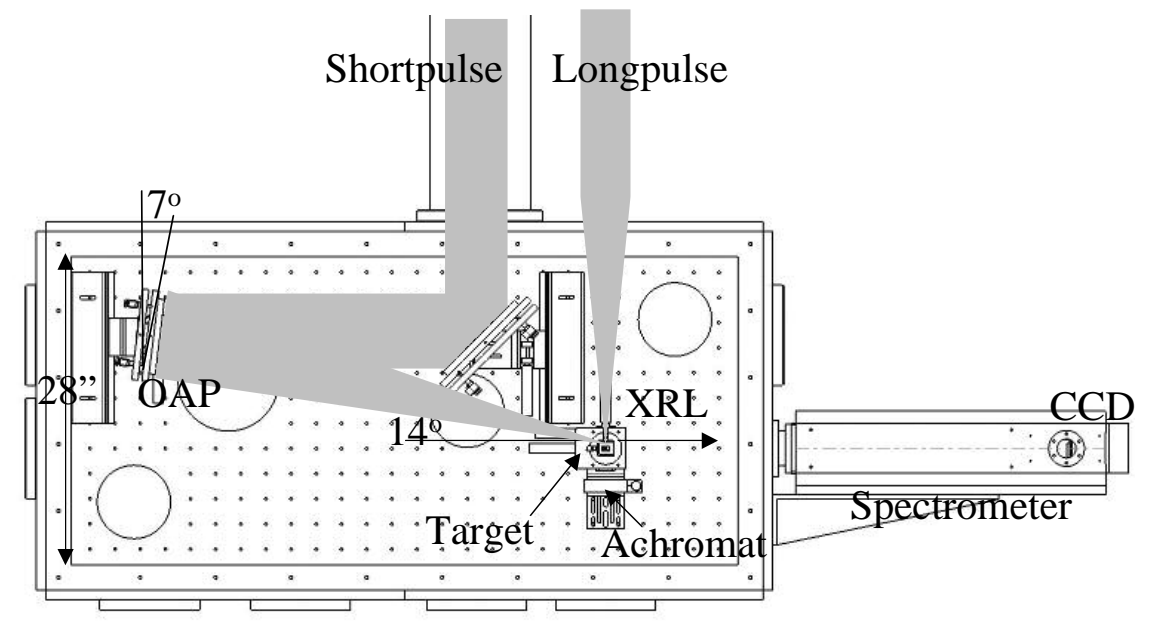

Figure 5 Experimental setup

a)

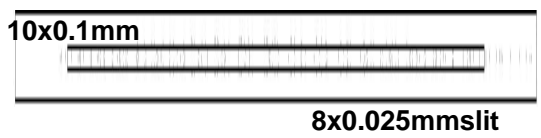

b)

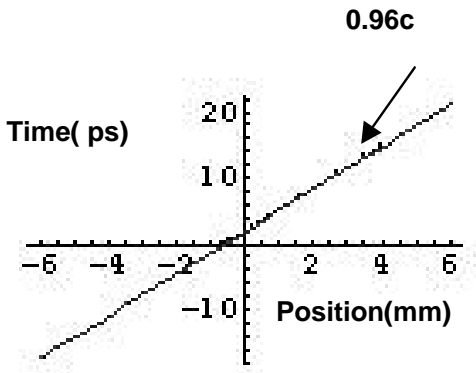

Figure 6 On axis parabola parameters a) line focus produced and b) traveling wave velocity 


\section{RESULTS}
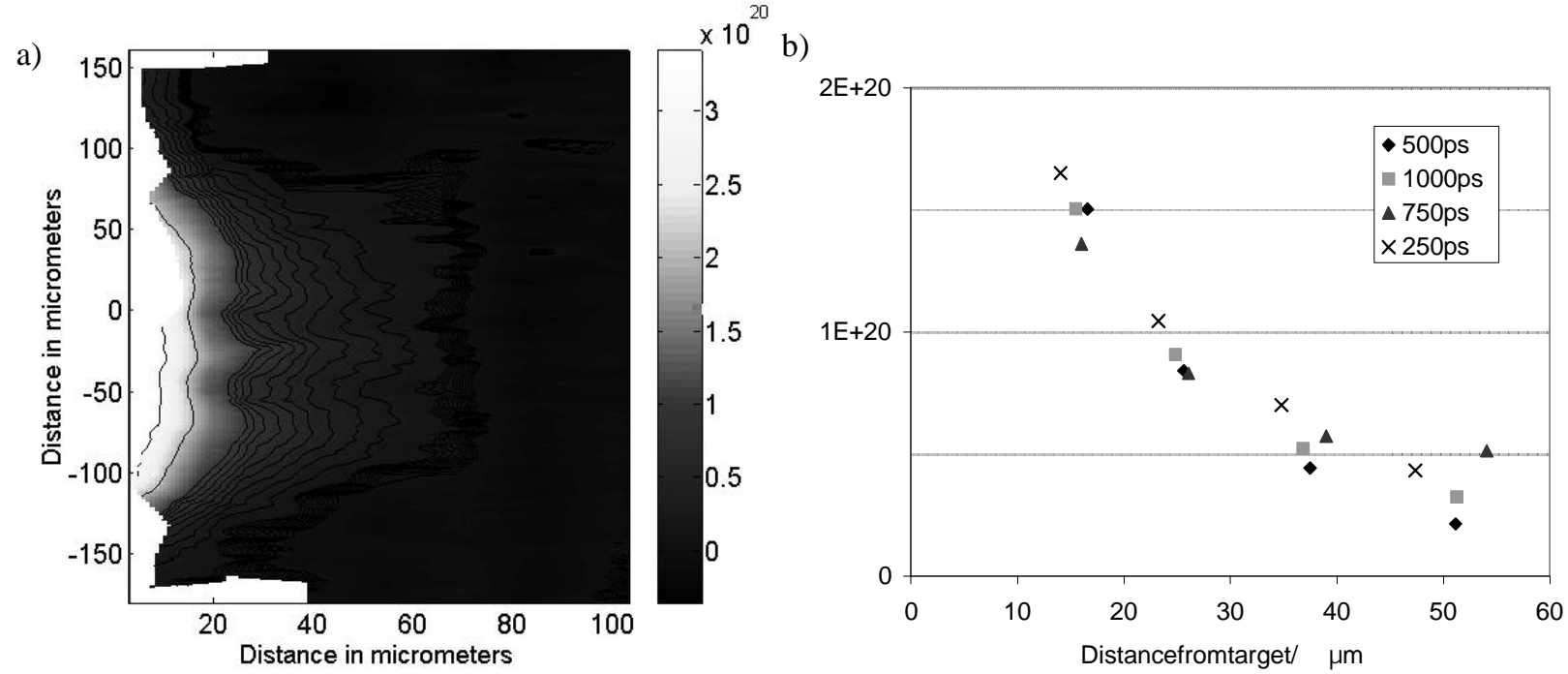

Figure 7 Electron density profiles measured by x-ray laser interferometry of Mo target irradiated with a 600 ps pulse at an intensity of $1 \times 10^{11} \mathrm{~W} / \mathrm{cm}^{2}$ a) 2-D density profile $500 \mathrm{ps}$ after the peak of the pulse b) lineout of density profile through center at different times

X-ray laser interferometry with a setup as in [2] was used to confirm the density profile for Mo targets irradiated under similar conditions to the modeling as described above. Interferometry of a $1 \mathrm{~mm}$ long Mo target irradiated in a line focus geometry with a $600 \mathrm{ps}$ pulse at intensity of $1 \times 10^{11} \mathrm{~W} / \mathrm{cm}^{2}$ was carried out. The resulting 2-D map of the electron density profile is shown in Figure 7 a). Shots were taken probing at different times after the peak of the pulse. The lineout through the center of the density profile for each of these is shown in Figure $7 \mathrm{~b}$ ) out to $60 \mu \mathrm{m}$ from the target. Close to the target the density profile does not appear to change much with time, but further from the target the plasma is expanding with time. The lineout for 500 ps shows a density profile similar to that produced in modeling, with a density of $10^{20} \mathrm{~cm}^{-3} 20 \mu \mathrm{m}$ from the target. Though the irradiation conditions are slightly different, using the longer $600 \mathrm{ps}$ laser pulse, this gives some confidence in the conditions within the gain region that might be achieved.

a)

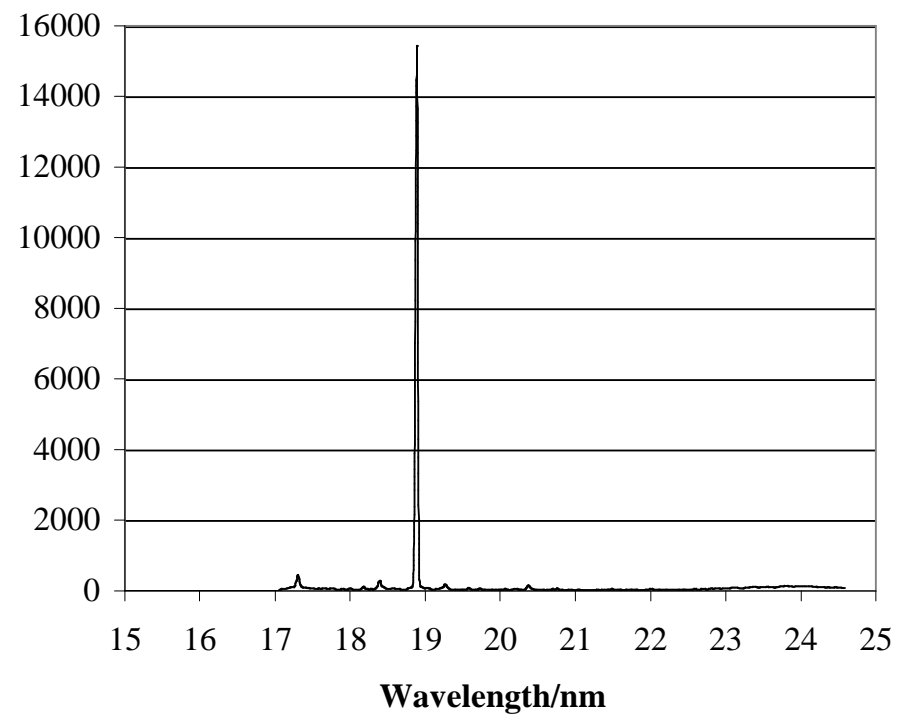

b)

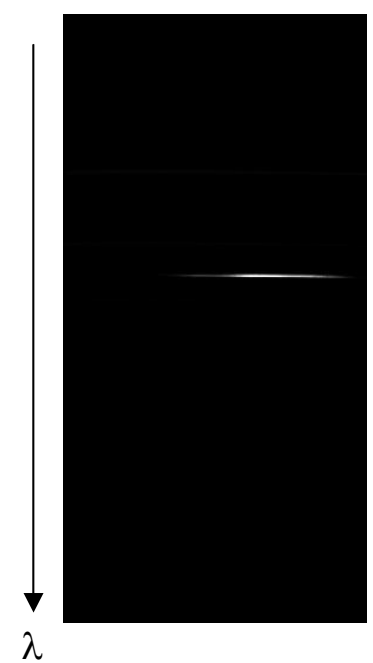

Figure 8 a) Soft x-ray spectrum from flat-field spectrometer for a single shot on Mo showing strong lasing at $18.9 \mathrm{~nm}$ and b) CCD image over the same wavelength range in the vertical and showing angular divergence in the horizontal direction 
The recorded spectrum for a single shot on Ni-like Mo is shown in Figure 8 with the lineout taken through the peak of the $\mathrm{x}$-ray laser. The spectrum was calibrated using the grating dispersion relation for this experimental setup [21]. The first experiments with the setup described above showed no lasing, but $\mathrm{Cu}$-like lines were identified in the spectra [22]. However the experiment has been repeated and when the line focus length of both beams was reduced to $\sim 4 \mathrm{~mm}$, and with this an improvement in the line focus quality and a reduced width, lasing was observed. These are preliminary results, with no optimization, but the lasing line at $18.9 \mathrm{~nm}$ is seen to completely dominate the spectrum in Figure 8 . This was achieved with $70 \mathrm{~mJ}$ in the short pulse with a pulse duration of $1.5 \mathrm{ps}$.

\section{CONCLUSIONS}

A new grazing incidence pumping scheme (GRIP) with increased efficiency will allow lower pump energy and high repetition rate of the optical pump beam. This new scheme has been described and modeling for Ni-like Mo at $18.9 \mathrm{~nm}$ presented. The experiment setup with grazing incidence pumping has already been already achieved and lasing has been observed. Working from this initial observation we will characterize this laser, measure the gain and hopefully achieve saturation. The peak brightness could be as high as $2.5 \times 10^{26}\left[\mathrm{Ph} . \mathrm{mm}^{-2} \mathrm{mrad}^{-2} \mathrm{~s}^{-1}(0.1 \% \mathrm{BW})^{-1}\right]$ with average brightness at $10 \mathrm{~Hz}$ repetition rate expected to be $2.5 \times 10^{14}$.

Pumping x-ray lasers with an optical pulse at other than perpendicular or axial angles has been reported in other work. Tommasini et al used a $150 \mathrm{fs,} 300 \mathrm{~mJ}$ pump beam at an angle of $30^{\circ}$ and observed Ni-like Mo lines [23]. However this angle was chosen primarily to produce the traveling wave. The photo-ionization pumped Xe III laser at $109 \mathrm{~nm}$ has been pumped with only $150 \mathrm{~mJ}$ in a grazing-incidence geometry [24. This scheme was also chosen to create traveling wave pumping but by modifying the target surface the angle of incidence on target was changed to near normal. We present the GRIP scheme as a novel idea since the grazing incidence angle is chosen specifically to improve coupling of the optical pump and hence the efficiency of the x-ray laser.

The major goal of this research was to produce a saturated $\mathrm{x}$-ray laser under $20 \mathrm{~nm}$ with less than $250 \mathrm{~mJ}$ optical pump showing the improvement in efficiency that can be achieved with grazing incidence pumping (GRIP). Once the x-ray laser has been characterized a beam-line will be setup for applications, which may include a number of areas including transient plasma interferometry as well as imaging and microscopy that would utilize this high average brightness source. Of particular interest would be the demonstration of a shorter wavelength XRL using this novel, high efficiency pumping geometry.

\section{ACKNOWLEDGMENTS}

The authors would like to thank J. Filevich and J. Rocca of Colorado State University for the analysis of the interferograms and production of the 2-D density profiles. The continued support of A. Osterheld is greatly appreciated. We acknowledge the technical contributions of J. Boyett, R. Van Maren, C. Bruns, R. Berry and J. Hunter. This work was performed under the auspices of the U.S. Dept. of Energy by the University of California Lawrence Livermore National Laboratory under Contract No. W-7405-Eng-48.

\section{REFERENCES}

1. J. J. Rocca, “Table-top soft x-ray lasers”, Rev. Sci. Inst., 70, 3799-3827, 1999

2. R. F. Smith, J. Dunn, J. Nilsen, V. N. Shlyaptsev, S. Moon, J. Filevich, J.J. Rocca, M.C. Marconi, J. R. Hunter, T.W. Barbee, Jr., "Picosecond X-Ray Laser Interferometry of Dense Plasmas", Phys. Rev. Lett., 89, 065004 1-4, 2002

3. D.L. Matthews, P.L. Hagelstein, M.D. Rosen, M.J. Eckart, N.M. Ceglio, A.U. Hazi, H. Medecki, B.J. MacGowan, J.E. Trebes, B.L. Whitten, E.M. Campbell, C.W. Hatcher, A.M. Hawryluk, R.L. Kauffman, L.D. Pleasance, G. Rambach, J.H. Scofield, G. Stone and T.A. Weaver, "Demonstration of a Soft X-ray Amplifier", Phys. Rev. Lett., 54, 110-113, 1985

4. J. Nilsen, B. MacGowan, L. B. DaSilva, J. C. Moreno, "Prepulse technique for producing low-Z Ne-like x-ray lasers", Phys. Rev. A, 48, 4682-4685, 1993 
5. J. Y. Lin, G. J. Tallents, R. Smith, A.G. MacPhee, E. Wolfrum, J. Zhang, G. Eker, R. Keenan, C.L.S. Lewis, D.Neely, R.M.N. O'Rourke, G.J. Pert, S. J. Pestehe and J.S. Wark, "Optimization of double pulse pumping for Nilike Sm x-ray lasers", J. Appl. Phys., 85, 672-675, 1999

6. S. Sebban, H. Daido, N. Sakaya, Y. Kato, K. Murai, H. Tang, Y. Gu, G. Huang, S. Wang, A. Klisnick, Ph. Zeitoun, F. Koike and H. Takenaka, "Full characterization of a high-gain saturated x-ray laser at 13.9 nm", Phys. Rev. A, 61, $0438101-9,2000$

7. R. Tommasini, F. Löwenthal and J. E. Balmer, "Saturation in a Ni-like Pd soft-x-ray laser at $14.7 \mathrm{~nm}$ ", Phys. Rev. A, 59, 1577-1581, 1999

8. B. Rus, T. Mocek, A.R. Prag, M. Kozlova, G. Jamelot, A. Carillon, D. Ros, D. Joyeux and D. Phalippou, "Multimillijoule, highly coherent $\mathrm{x}$-ray laser at $21 \mathrm{~nm}$ operating in deep saturation through double-pass amplification" Phys. Rev. A, 66, 063806 1-12, 2002

9. R.Smith, G.J. Tallents, J. Zhang, G.Eker, S. McCabe, G.J. Pert and E. Wolfrum, "Saturation behavior of two x-ray lasing transitions in Ni-like Dy", Phys. Rev. A, 59, R47-R50, 1999

10. P.V. Nickles, V.N. Shlyapstev, M. Kalachnikov, M. Schnurer, I. Will and W. Sandner, "Short Pulse X-Ray Laser at 32.6 nm Based on Transient Gain in Ne-like Titanium", Phys. Rev. Lett., 78, 2748-2751, 1997

11. R. E. King, G. J. Pert, S. P. McCabe, P. A. Simms, A. G. MacPhee, C. L. S. Lewis, R. Keenan, R. M. N. O'Rourke,G. J. Tallents, S. J. Pestehe, F. Strati, D. Neely, and R. Allott, "Saturated x-ray lasers at 196 and $73 \AA$ pumped by a picosecond traveling-wave excitation”, Phys. Rev. A, 64, 053810 1-12, 2001

12. A. Klisnick,J. Kuba, D. Ros, R. Smith, G. Jamelot, C. Chenais-Popovics, R. Keenan, S. J. Topping, C. L. S. Lewis, F. Strati, G. J. Tallents, D. Neely, R. Clarke, J. Collier, A. G. MacPhee, F. Bortolotto, P. V. Nickles, and K. A. Janulewicz, "Demonstration of a 2-ps transient x-ray laser", Phys. Rev. A, 65, 033810 1-4, 2002

13. 13. J. Dunn, Y. Li, A.L. Osterheld, J. Nilsen, J.R. Hunter, V.N. Shlyaptsev, "Gain Saturation Regime for LaserDriven Tabletop, Transient Ni-Like Ion X-Ray Lasers”, Phys. Rev. Lett., 84, 4834-4837, 2000

14. J. Dunn, et al., these proceedings

15. S. Sebban, R. Haroutunian, Ph. Balcou, G. Grillon, A. Rousse, S. Kazamias, T. Marin, J. P. Rousseau,L. Notebaert, M. Pittman, J. P. Chambaret, A. Antonetti, D. Hulin, D. Ros, A. Klisnick, A. Carillon,P. Jaeglé, G. Jamelot, and J. F. Wyart, "Saturated Amplification of a Collisionally Pumped Optical-Field-Ionization Soft X-Ray Laser at 41.8 nm", Phys. Rev. Lett., 86, 3004-3007, 2001

16. S. Sebban, T. Mocek, D. Ros, L. Upcraft, Ph. Balcou, R. Haroutunian, G. Grillon, B. Rus, A. Klisnick, A. Carillon, G. Jamelot, C. Valentin, A. Rousse, J. P. Rousseau, L. Notebaert, M. Pittman, and D. Hulin, "Demonstration of a $\mathrm{Ni}$ Like Kr Optical-Field-Ionization Collisional Soft X-Ray Laser at 32.8 nm”, Phys. Rev. Lett., 89, 253901 1-4, 2002

17. T. Ozaki, R. A. Ganeev, A. Ishizawa, T. Kanai, and H. Kuroda, "Highly Directive $18.9 \mathrm{~nm}$ Nickel-like Molybdenum X-Ray Laser Operating at 150 mJ Pump Energy", Phys. Rev. Lett., 89, 253902 1-4 2002

18. C. D. Macchietto, B. R. Benware, and J. J. Rocca, "Generation of millijoule-level soft-x-ray laser pulses at a 4-Hz repetition rate in a highly saturated tabletop capillary discharge amplifier", Optics Letters, 24, 1115-1117, 1999

19. V.L. Ginzburg, Propagation of Electromagnetic Waves in Plasma, Addison-Wesley, Reading, 1964

20. V. Shlyaptsev, et al., these proceedings

21. T. Kita, T. Harada, N. Nakano and H. Kuroda, "Mechanically ruled aberration-corrected concave gratings for a flatfield grazing-incidence spectrograph”, Appl. Opt., 22, 512-513, 1983

22. J. Reader, G. Luther and N. Acquista, "Spectrum and energy levels of thirteen-times ionized molybdenum (Mo XIV)", J. Opt. Soc. Am., 69, 144-149, 1979

23. R. Tommasini, J. Nilsen and E.E. Fill, "Investigations on 10-Hz sub-Joule fs-laser pumped neon- and nickel-like X-ray lasers”, Soft X-ray Lasers and Applications IV, Ernst E. Fill, Jorge J. G. Rocca, Editors, Proceedings of SPIE Vol. 4505, 85-92, 2001

24. H. Yamakoshi, P. R. Herman, M. P. Le Flohic, B. Xiao, L. Zhao, G. Kulcsar, F. W. Budnik, and R. S. Marjoribanks, "Picosecond pumping of extreme-ultraviolet lasers using preformed laser plasmas", J. Opt. Soc. Am. B, 13, 436-442, 1996 